\title{
The Gifted Yet Broken Healer
}

Rumaila Hussain

\section{Gifted healer she called me}

Drawn to the world of medicine like a moth to a flame to heal those broken

Yet, I became broken in the process

Eat, sleep, breathe, medicine, they warned me, but little did I know what they truly meant

I chose to devote myself to my future patients, but I forgot to nurture my own soul, I forgot who I was, I lost my identity

I forgot that I too was a daughter, sister, aunt, girlfriend

Medicine does not mean you must become a martyr

Love yourself, as you cannot heal others when you are broken

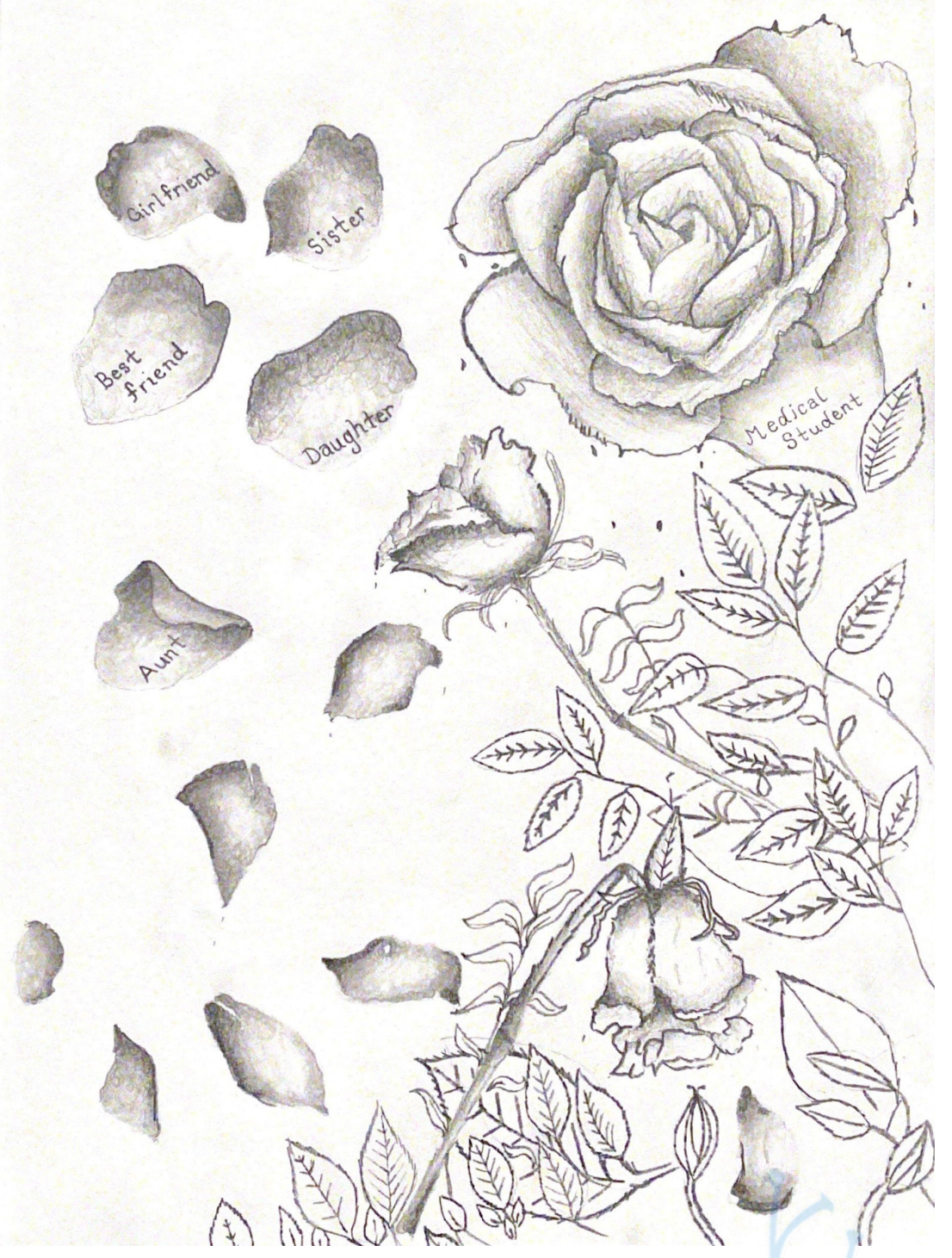

Illustrated By: Jaime Hernandez 